NASA Technical Memorandum 105809

AIAA-92-3622

\title{
An Experimental Investigation of the Flow in a Diffusing S-Duct
}

Steven R. Wellborn

Iowa State University

Ames, Iowa

Bruce A. Reichert

Lewis Research Center

Cleveland, Ohio

and

Theodore H. Okiishi

Iowa State University

Ames, Iowa

Prepared for the

28th Joint Propulsion Conference and Exhibit

cosponsored by the AIAA, SAE, ASME, and ASEE

Nashville, Tennessee, July 6-8, 1992 


\title{
AN EXPERIMENTAL INVESTIGATION OF THE FLOW IN A DIFFUSING S-DUCT
}

\author{
S. R. Wellborn* \\ Iowa State University, Ames, Iowa \\ B. A. Reichert ${ }^{\dagger}$ \\ NASA Lewis Research Center, Cleveland, Ohio \\ T. H. Okiishi ${ }^{\ddagger}$ \\ Iowa State University, Ames, Iowa
}

\begin{abstract}
Compressible, subsonic flow through a diffusing Sduct has been experimentally investigated. Benchmark aerodynamic data are presented for flow through a representative S-duct configuration. The collected data would be beneficial to aircraft inlet designers and is suitable for the validation of computational codes. Measurements of the three dimensional velocity field and total and static pressures were obtained at five cross-sectional planes. Surface static pressures and flow visualization also helped to reveal flow field characteristics. All reported tests were conducted with an inlet centerline Mach number of 0.6 and a Reynolds number, based on the inlet centerline velocity and duct inlet diameter, of $2.6 \times 10^{6}$. The results show that a large region of streamwise flow separation occurred within the duct. Details about the separated flow region, including mechanisms which drive this complicated flow phenomenon, are discussed. Transverse velocity components indicate that the duct curvature induces strong pressure driven secondary flows, which evolve into a large pair of counter-rotating vortices. These vortices convect the low momentum fluid of the boundary layer towards the center of the duct, degrading both the uniformity and magnitude of the total pressure profile.
\end{abstract}

Nomenclature

$\begin{array}{lll}A & = & \text { duct cross-sectional area } \\ C & = & \text { sonic velocity } \\ C p & = & \text { static pressure coefficient } \\ C p_{o} & = & \text { total pressure coefficient } \\ d & = & \text { inlet duct diameter } \\ H & = & \text { boundary layer shape factor }\left(\delta_{1} / \delta_{2}\right) \\ M & = & \text { Mach number }\end{array}$

*Research Assistant, Mechanical Engineering Department, Student Member AIAA.

${ }^{\dagger}$ Aerospace Engineer, Inlet, Duct, and Nozzle Flow Physics Branch, Member AIAA.

‡Professor and Chair, Mechanical Engineering Department, Member AIAA.

Copyright $\odot 1992$ by the American Institute of Acronautics and Astronautics, Inc. No copyright is asserted in the United States under Title 17, U.S. Code. The U.S. Government has a royalty-free license to exercise all rights under the copyright claimed herein for Governmental purposes. All other rights are reserved by the copyright owner.

$\mathrm{M}$
$p$
$p_{0}$
$s$
$r$
$R$
$\operatorname{Re}$
$u^{+}$
$x, y, z$
$y^{+}$
$\delta$
$\delta_{1}$
$\delta_{2}$
$\theta$
$\phi$

$=$ normalized Mach number

$=\quad$ static pressure

$=$ total pressure

$=\quad$ center line arc length

$=$ duct cross-sectional radius

$=$ duct curvature radius

$=$ Reynolds number

= law-of-the-wall ordinate

$=\quad$ cartesian coordinate system

= law-of-the-wall abscissa

$=$ boundary layer thickness

$=$ displacement thickness

$=$ momentum thickness

$=$ duct substended angle

$=$ cross-stream polar angle

Subscripts

$\begin{array}{lll}c l & = & \text { centerline } \\ 1 & = & \text { station at beginning of curvature } \\ 2 & = & \text { station at end of curvature }\end{array}$

Introduction

ARCRAFT propulsion systems often use diffusing Sducts to convey air flow from the wing or fuselage intake to the engine compressor. Compressible, subsonic flow conditions usually exist for this application. Examples of commercial aircraft with S-ducts include the Boeing 727 and Lockheed Tristar. Amongst military aircraft, both the General Dynamics F-16 and McDonnellDouglas F-18 use S-shaped ducts.

Well designed diffusing S-ducts should efficiently decelerate the incoming flow. To achieve appropriate engine performance, the S-duct must also incur minimal total pressure losses and deliver nearly uniform flow with small transverse velocity components at the engine compressor entrance. Unfortunately, the centerline curvature associated with S-ducts generates significant secondary flows. In addition, a cross-sectional area increase makes flow separation likely. Secondary flows and flow separation can result in unacceptable duct performance.

A few investigators have experimentally studied Sduct flows, obtaining measurements with pressure probes and laser anemometry. ${ }^{1-4}$ Considerable computational 


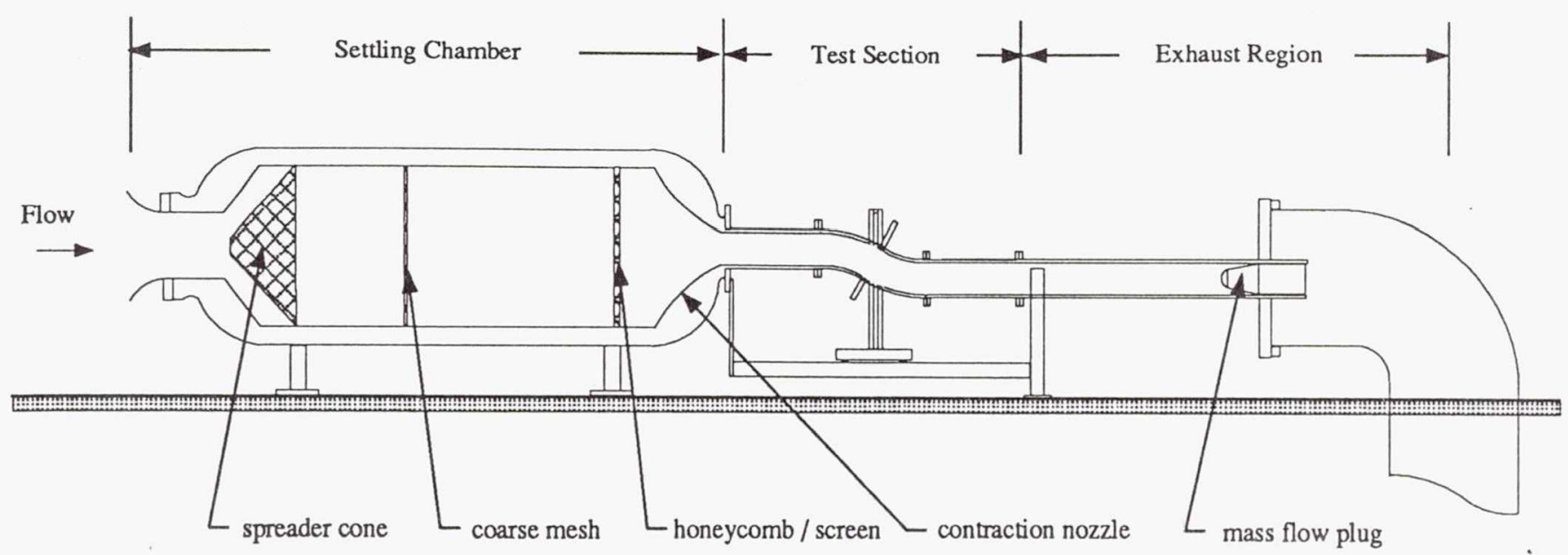

Fig. 1 Schematic of Internal Fluid Mechanics Facility.

effort has also been focused on the complicated threedimensional flows through S-ducts. Researchers at the NASA Lewis Research Center recently turned their attention to complete Navier-Stokes analyses, ${ }^{5-7}$ following much effort using reduced Navier-Stokes equations. ${ }^{8-11}$ These studies suggest the formation of a pair of counterrotating vortices located within an S-duct. Streamwise flow separation was also a dominant feature for S-ducts with large centerline displacements and/or cross-sectional area increases. From a design point, the ability to predict complicated three dimensional flow phenomena without extensive experimental testing is desirable. However, only a limited amount of benchmark data exists for the validation of computational fluid dynamics codes applied to compressible S-duct flows.

The objective of this study was to provide a comprehensive benchmark data set for the compressible flow through a representative diffusing S-duct. Also, details of the flow separation region and the mechanisms which drive this complicated flow phenomenon were investigated. The detailed aerodynamic data are suitable for validating computational fluid dynamics methods. The experimental data were acquired along with a concurrent computational effort, with considerable beneficial synergism resulting from the combination. This concurrent approach also proved to be successful in a recent study of circular-to-rectangular transition duct flows. ${ }^{12,13}$

\section{Experimental Facility}

Detailed data for the flow through a circular cross section diffusing S-duct were acquired using the NASA Lewis Research Center Internal Fluid Mechanics Facility. Complete details of the facility are described by Porro et al. ${ }^{14}$ This facility was designed to support tests of a variety of internal flow configurations. For this experiment, atmospheric test cell air was drawn through a large settling chamber, passed through the test section and dumped into a large exhaust plenum. A schematic of the facility is shown in Fig. 1.
The settling chamber conditioned the incoming flow with a series of wires, meshes and screens. First, a perforated spreader cone mixed the inlet flow. Second, a coarse mesh conditioning screen reduced mean flow nonuniformities. Finally, a honeycomb-screen combination removed large scale turbulence fluctuations. A contraction section uniformly accelerated the flow from the settling chamber. An area contraction ratio of 59 ensured a low turbulence intensity flow field at the test region entrance.

The test section consisted of the diffusing S-duct and two constant area circular extensions. The first extension served as the interface between the contraction exit and the S-duct entrance. The second conveyed the flow from the S-duct to the exhaust region. Each extension was $76.2 \mathrm{~cm}$ long and of appropriate diameter.

The exhaust region contained a circular pipe, a mass flow plug and a sub-atmospheric plenum. The pipe, $244 \mathrm{~cm}$ long, housed the adjustable mass flow plug and ensured no downstream influence of the exhaust plenum on the test section. The mass flow plug controlled the airflow through the entire facility. Flow was simply dumped into the exhaust plenum after passing the mass flow plug.

\section{Diffusing S-Duct Geometry}

The diffusing S-duct was intentionally designed to incorporate a number of complex three dimensional flow features, including separation, which are associated with similar configurations. The geometry of the diffusing Sduct is shown in Fig. 2. The duct centerline was defined by two planar circular arcs with identical radii, $R$, of $102.1 \mathrm{~cm}$ and subtended angles, $\theta_{\max } / 2$, of $30^{\circ}$. The centerline coordinates, given by Eq. (1), are indicated by the dashed line in Fig. 2. All cross sections perpendicular to the centerline were circular. The duct inlet radius, $r_{1}$, was $10.21 \mathrm{~cm}$. The duct exit radius, $r_{2}$, was 12.57 $\mathrm{cm}$, which produced an area ratio, $A_{2} / A_{1}$, of 1.52 . The 
variation of the duct radius as a function of the angle $\theta$ is given by Eq. (2). The duct is larger than, but geometrically similar to, the duct tested by Vakili $e t$ $a l .{ }^{4}$ When discussing results, axial position will refer to the distance to the cross-stream planes measured along the duct centerline, beginning at the start of curvature. Positions within any cross-stream plane are specified by the polar angle $\phi$, measured from positive z-axis, and the radial distance $r$ from the centerline.

$$
\text { For } \begin{aligned}
0 & \leq \theta \leq \theta_{\max } / 2 \\
x_{c l} & =R \sin \theta \\
y_{c l} & =0 \\
z_{c l} & =R \cos \theta-R
\end{aligned}
$$

$$
\begin{aligned}
& \text { For } \theta_{\max } / 2 \leq \theta \leq \theta_{\max } \\
& \begin{aligned}
x_{c l} & =2 R \sin \left(\theta_{\max } / 2\right)-R \sin \left(\theta_{\max }-\theta\right) \\
y_{c l} & =0 \\
z_{c l} & =2 R \cos \left(\theta_{\max } / 2\right)-R-R \cos \left(\theta_{\max }-\theta\right)
\end{aligned}
\end{aligned}
$$

$$
\frac{r}{r_{1}}=1+3\left(\frac{r_{2}}{r_{1}}-1\right)\left(\frac{\theta}{\theta_{\max }}\right)^{2}-2\left(\frac{r_{2}}{r_{1}}-1\right)\left(\frac{\theta}{\theta_{\max }}\right)_{(2)}^{3}
$$

The duct was milled from two separate blocks of aluminium and had a final tolerance of $\pm 0.0127 \mathrm{~cm}$. After milling, the two halves were mated together, machining imperfections were removed, and the surface was polished. The interior split line, located on the vertical centerline plane, was flush to touch and invisible to sight.

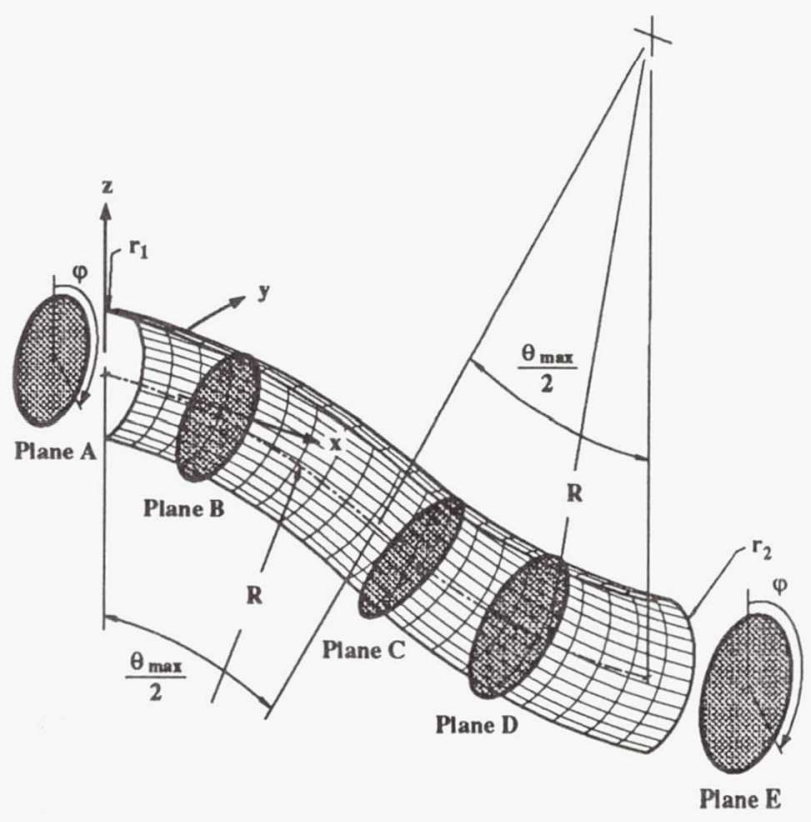

Fig. 2 Half shell of the circular diffusing S-duct.

\section{Instrumentation and Measurement Techniques}

The flow field was investigated by a variety of methods. The internal flow field was measured with calibrated three-and five-hole probes. Data were accumulated in five measurement planes, each perpendicular to the duct centerline. The measurement plane locations are presented in Table 1. These planes are also depicted by the shaded cross sections in Fig. 2. At each plane the S-duct contained port holes, allowing probe access to the flow. The number of port holes and measurement positions contained in each plane are also listed in Table 1. Reported internal flow measurements were concentrated in only one symmetric half of the duct. A three-hole probe was used at Plane A, since a one-directional velocity field existed there. A five-hole probe was used at the other four planes, enabling total pressure, static pressure and three components of velocity to be measured. Both yaw-nulling and non-yaw-nulling methods were employed. Flow phenomena were also studied with surface static pressure data. A total of 220 static pressure taps were located on the surface of the duct. The taps were positioned axially at constant angles $\phi=10^{\circ}, 90^{\circ}$, and $170^{\circ}$ and also circumferentially at Planes A, B, C and D. All reported aerodynamic data was taken as an arithmetic average of a number of measurements. The characteristics of the near surface flow were visualized by applying fluorescent oil to the surface. For this technique, a powder fluorescent dye was mixed with $140 \mathrm{wt}$. oil and then applied to the surface in small dots. Surface streakline patterns developed while air was drawn through the duct. The duration of the test, at the desired flow rate, was ten minutes.

Table 1 Measurement plane information.

\begin{tabular}{cccccc}
\hline \hline Plane & $\mathrm{A}$ & $\mathrm{B}$ & $\mathrm{C}$ & $\mathrm{D}$ & $\mathrm{E}$ \\
$\mathrm{s} / \mathrm{d}$ & -0.50 & 0.96 & 2.97 & 4.01 & 5.73 \\
Ports & 10 & 11 & 11 & 11 & 19 \\
Points & 590 & 462 & 506 & 539 & 930 \\
\hline \hline
\end{tabular}

All pressure data were obtained with a PSI measurement system. The fully integrated instrument consisted of electronically scanned pressure transducers and a microcomputer based data acquisition system. Individual pressure transducers provided high data acquisition rates for multiple pressure measurements. The accuracy of each transducer was maintained by frequent on line three-point calibrations. After acquisition, information was carried by Escort, a data routing network, to a storage area for later post-processing on Sun SPARCstations.

An L. C. Smith actuator was used to position all probes. Both translational and rotational motions were possible. Positions were measured by voltage potentiometers to ensure accurate location documentation. 
Inlet flow conditions were obtained from a survey of the flow field one radius upstream of the first bend (Plane A). All reported tests were conducted with an inlet centerline Mach number of 0.6. The Reynolds number, based on the inlet diameter and centerline velocity, was $2.6 \times 10^{6}$. A thin turbulent inlet boundary layer existed. A representative inlet velocity profile, plotted in nondimensional law-of-the-wall coordinates, is shown in Fig. 3. Comparisons indicated little deviation from a conventional turbulent profile. Boundary layer parameters are listed in Table 2 . The boundary layer thickness, $\delta$, corresponds to $95 \%$ of the free stream velocity. The displacement thickness, $\delta_{1}$, momentum thickness, $\delta_{2}$, and shape factor, $\mathrm{H}$, were calculated by numerically integrating the survey data, implementing a trapezoidal approximation.

Table 2 Inlet boundary layer parameters.

\begin{tabular}{|c|c|}
\hline \hline Profile Parameter & Calculated Value \\
\hline$\left(\delta / r_{1}\right) \times 100$ & 6.95 \\
$\left(\delta_{1} / r_{1}\right) \times 100$ & 1.46 \\
$\left(\delta_{2} / r_{1}\right) \times 100$ & 1.06 \\
$H$ & 1.38 \\
\hline \hline
\end{tabular}

\section{Results and Discussion}

All data presented in this paper are in nondimensional form. Aerodynamic results represent mean values. Pressures are presented as total and static pressure coefficients, which are defined by Eqs. (3) and (4). The pressures $p_{o}$ and $p$ represent local values of total and static pressure. Inlet centerline conditions define the reference states $p_{o, c l}$ and $p_{c l}$. Three dimensional velocity components were converted to local Mach vectors and normalized by the inlet centerline Mach number, as shown in Eq. (5).

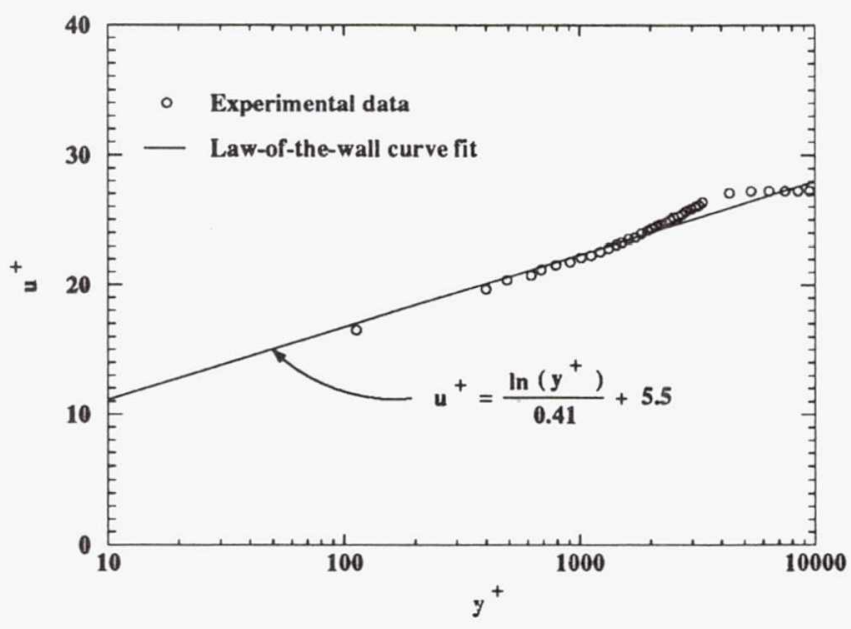

Fig. 3 Typical law-of-the-wall velocity profile.

$$
\begin{gathered}
C_{p_{0}}=\frac{p_{o}-p_{c l}}{p_{o, c l}-p_{c l}} \\
C_{p}=\frac{p-p_{c l}}{p_{o, c l}-p_{c l}} \\
\mathbf{M}=\frac{\mathbf{V} / c}{M_{c l}}
\end{gathered}
$$

For this section the nondimensional pressure coefficients will simply be referred to as total and static pressures. The velocity vector will be presented as normal and transverse components. The normal component is perpendicular to the measurement plane while the transverse component is parallel to the measurement plane. Since data were taken in only one half of the duct, all internal plane results have been mirror imaged for presentation.

\section{Flow Visualization}

Major flow field characteristics were visualized by streaklines of fluorescent oil on the duct surface. Three conclusions were made from the streakline patterns. First, the flow was indeed symmetric. This was ascertained by applying different color dye to each symmetric duct half. The dye from each half remained separate. Second, a large region of separated flow existed, as strikingly indicated in Figs. 4 and 5. The entire duct section is shown in Fig. 4, while Fig. 5 is a close up of the separated region. The free stream flow is from left to right and each photo shows only one symmetric half of the observed streakline pattern. The separated region consisted of two saddle points, occurring on the duct split line $\left(\phi=180^{\circ}\right)$, and two spiral nodes, lying in each symmetric duct half. The entire separated region was located on the lower wall. The onset of separation (upstream saddle point) was located at $\mathrm{s} / \mathrm{d}=2.02$, while reattachment (downstream saddle point) occurred at $\mathrm{s} / \mathrm{d}=$ 4.13. Third, boundary layer cross flows were present. In the first bend, streaklines were driven towards the lower surface $\left(\phi=180^{\circ}\right)$. In the second bend, the streaklines near $\phi=90^{\circ}$ diverged. The upper streaklines converged towards the top of the duct, while the lower streaklines continued towards the lower split line $\left(\phi=180^{\circ}\right)$.

A qualitative assessment of the flow in the plane of symmetry ( $\mathrm{x}-\mathrm{z}$ plane) was acquired by temporarily introducing a splitter plate, which divided the two symmetric duct halves. The plate was installed for only one test in order to produce streakline patterns. The S-duct surface results given above were obtained without the splitter plate in place. The splitter plane results are assumed to be qualitatively correct, even though the presence of the flat plate introduced additional shear into the flow. The streakline patterns produced on the splitter plate are presented in Fig. 6. Free stream flow is from left to right. 


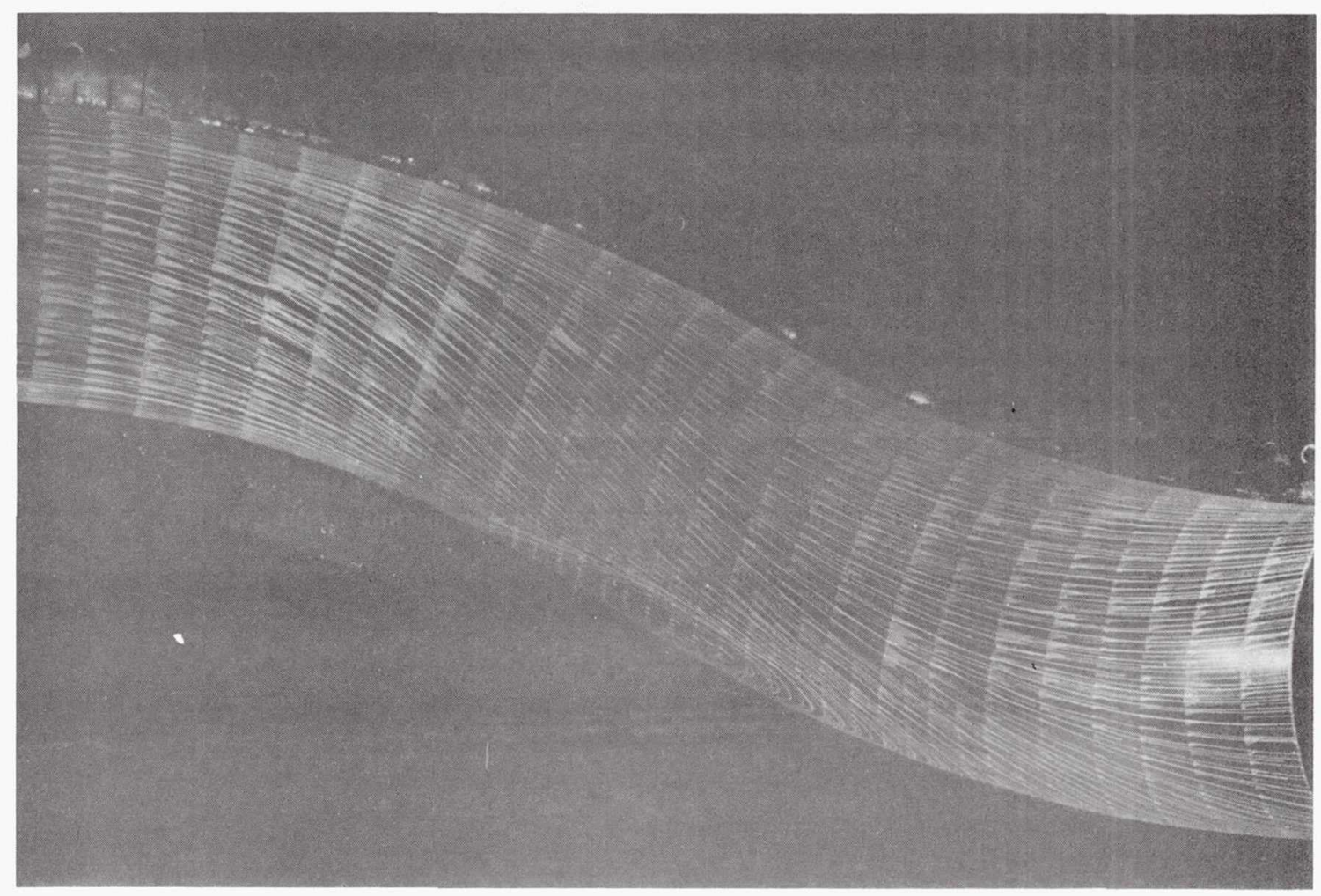

Fig. 4 Surface oil flow patterns on one symmetric half of the duct surface.

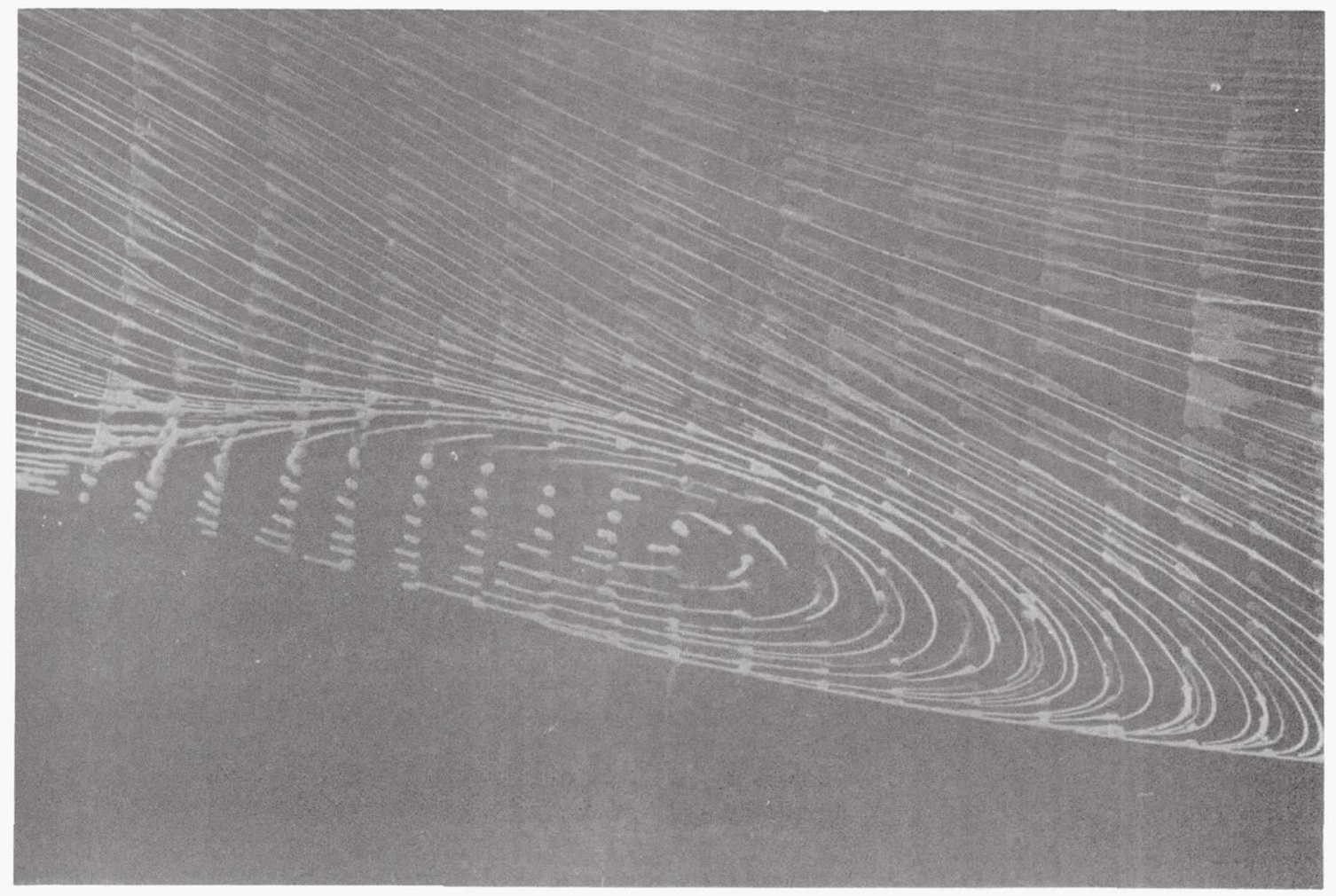

Fig. 5 Close up of the surface oil flow patterns developed in the separation region. 


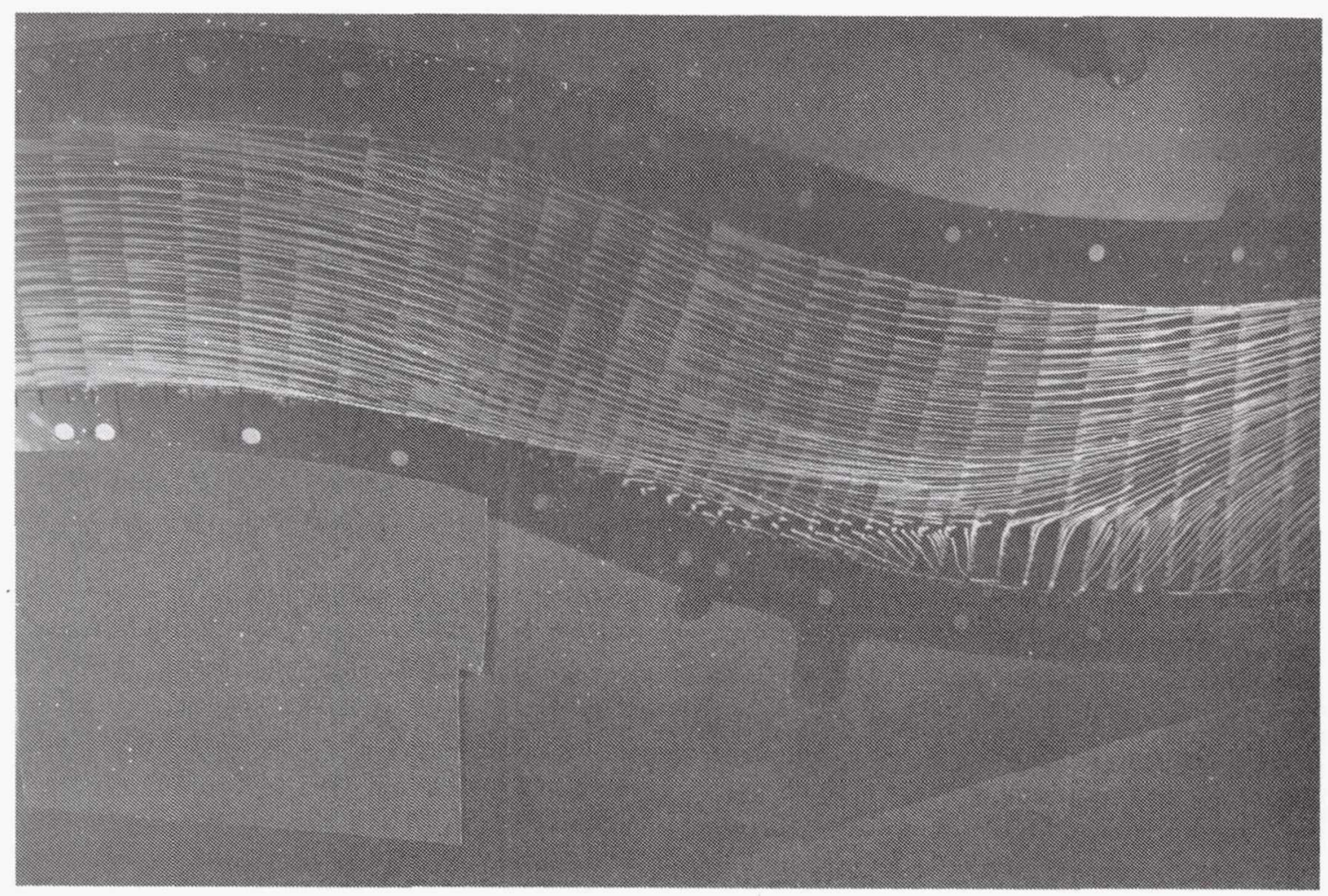

Fig. 6 Surface oil flow patterns on the centerline splitter plate.

The location of separation and reattachment are identifiable. The streaklines follow the duct curvature in the first bend. However, blockage caused by separation forced the streaklines to deviate from the curvature of the second bend. The reversed flow region began thin and appeared to grow until reattachment. A strong vortical structure followed reattachment. Viscous effects associated with the splitter plate can be seen by the extensive bending of the streaklines at the exit of the duct. Cross-stream pressure gradients helped drive the boundary layer fluid on the splitter plate towards the top of the duct. This

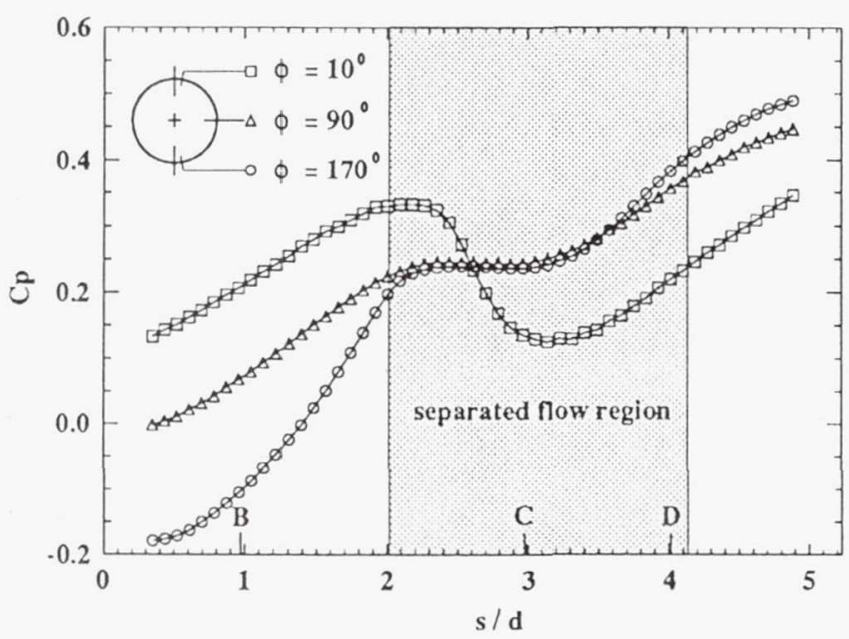

Fig. 7 Axial distribution of surface static pressures for three circumferential positions. was most noticeable at the exit where the splitter plate boundary layer was the thickest.

\section{Surface Static Pressures}

Symbols in Fig. 7 represent the static pressure variation with axial distance for three circumferential locations. The region of streamwise separated flow, deduced from flow visualization, is also shown. The effects of streamline curvature and diffusion are clearly indicated during the first bend by the pressure difference between

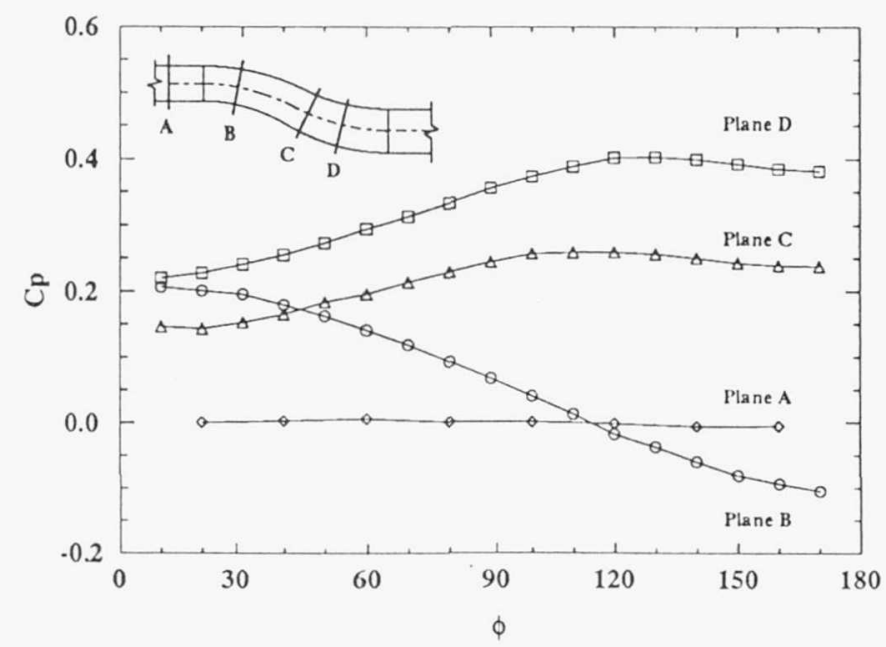

Fig. 8 Circumferential distribution of surface static pressures at four axial locations. 


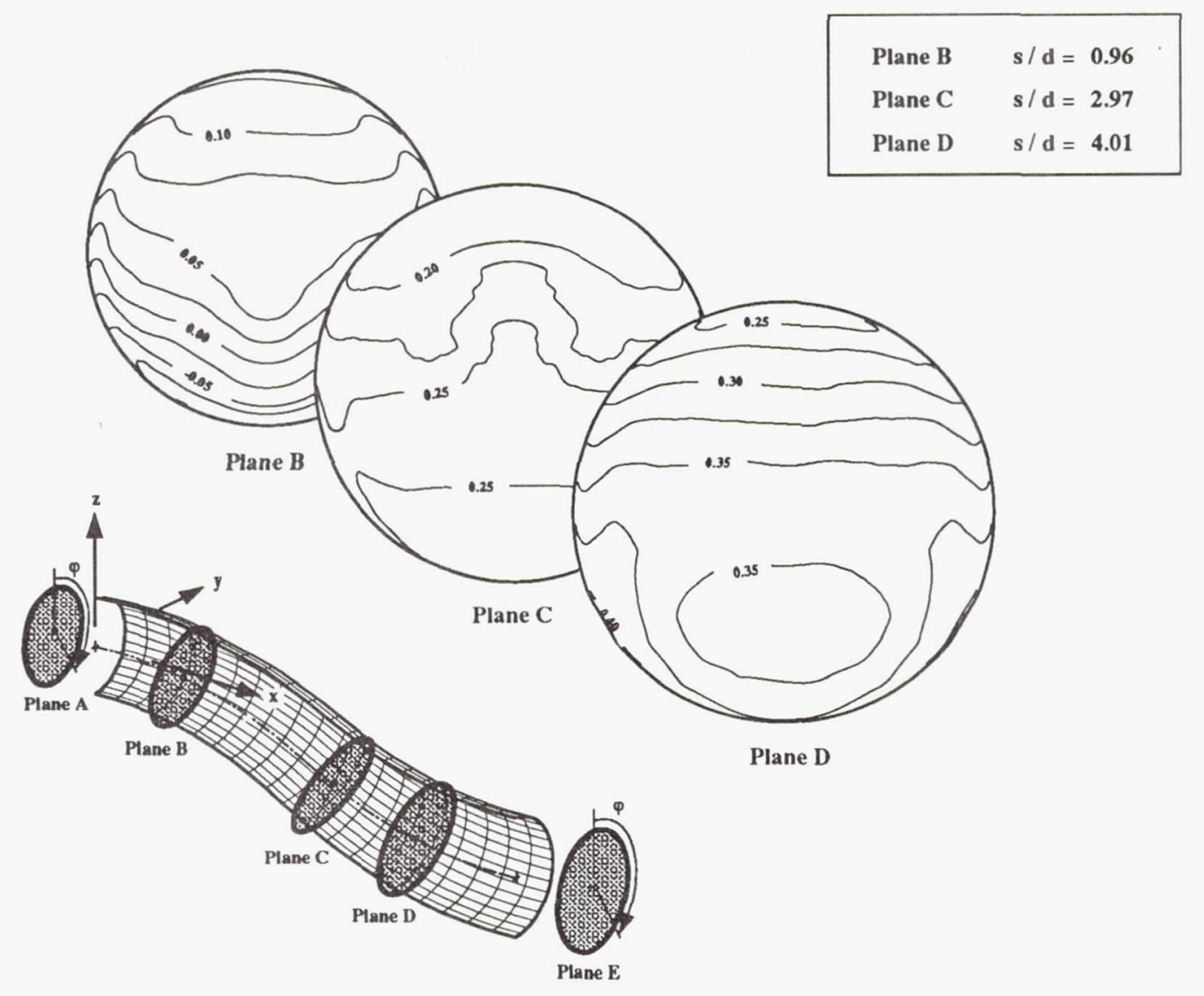

Fig. 9 Static pressures in three interior planes.

$\phi=10^{\circ}$ and $170^{\circ}$ and overall pressure rise, respectively. The influence of separation is shown by the constant values of the $\phi=90^{\circ}$ and $170^{\circ}$ static pressures between $2.0<s / d<3.2$. The proximity of these two curves, between $2.0<s / d<3.2$, indicate minimal change in flow speed or direction in the lower half of the duct. The blockage, caused by the separated region, also helped to produce a favorable pressure gradient at $\phi=10^{\circ}$. Static pressures at the three angles are nearly equal at $s / d=2.6$, suggesting a constant static pressure distribution throughout the cross-stream plane. The static pressure rose again for $s / d>3.2$, even though the flow remained separated beyond this region, because the duct continued to diffuse. After reattachment the pressures distributions converge, although not plotted, to $C p=0.466$ far downstream $(s / d \approx 9.0)$.

The circumferential distribution of surface static pressure in Planes A through D is presented in Fig. 8. The pressures for Plane A are nearly equal indicating no influence of the duct curvature at this upstream section. The data for Planes B, C and D all reflect the presence of streamline curvature. The pressures measured in Plane B are maximum at $\phi=10^{\circ}$ and continually descend until $\phi=170^{\circ}$. The values are negative for $\phi>110^{\circ}$. Sepa- ration has not affected the flow field yet. In Planes $\mathrm{C}$ and $\mathrm{D}$ the cross-stream pressure gradient has reversed. However, the influence of separation can be seen by the slight drop in pressure at large values of $\phi$. The surface static pressures also indicate the separation region has reduced in size from Plane $\mathrm{C}$ to $\mathrm{D}$.

\section{Internal Aerodynamic Data}

Contours of static pressure are shown in Fig. 9 for the Planes B, C and D. Static pressure data indicated a nearly uniform cross-stream static pressure distribution at Planes $\mathrm{A}$ and $\mathrm{E}$ and therefore are not presented. The values of static pressure very near the duct surface in Fig. 9 are in excellent agreement with the data obtained from surface static pressure taps shown in Fig. 8.

Total pressure distributions for the five planes are presented as contours in Fig. 10. Expanded views of the distributions of total pressure for Planes A and B are also included in order to help distinguish the boundary layer contours. The convection of boundary layer fluid away from the surface into the core flow is quite pronounced at Planes C, D and E. 


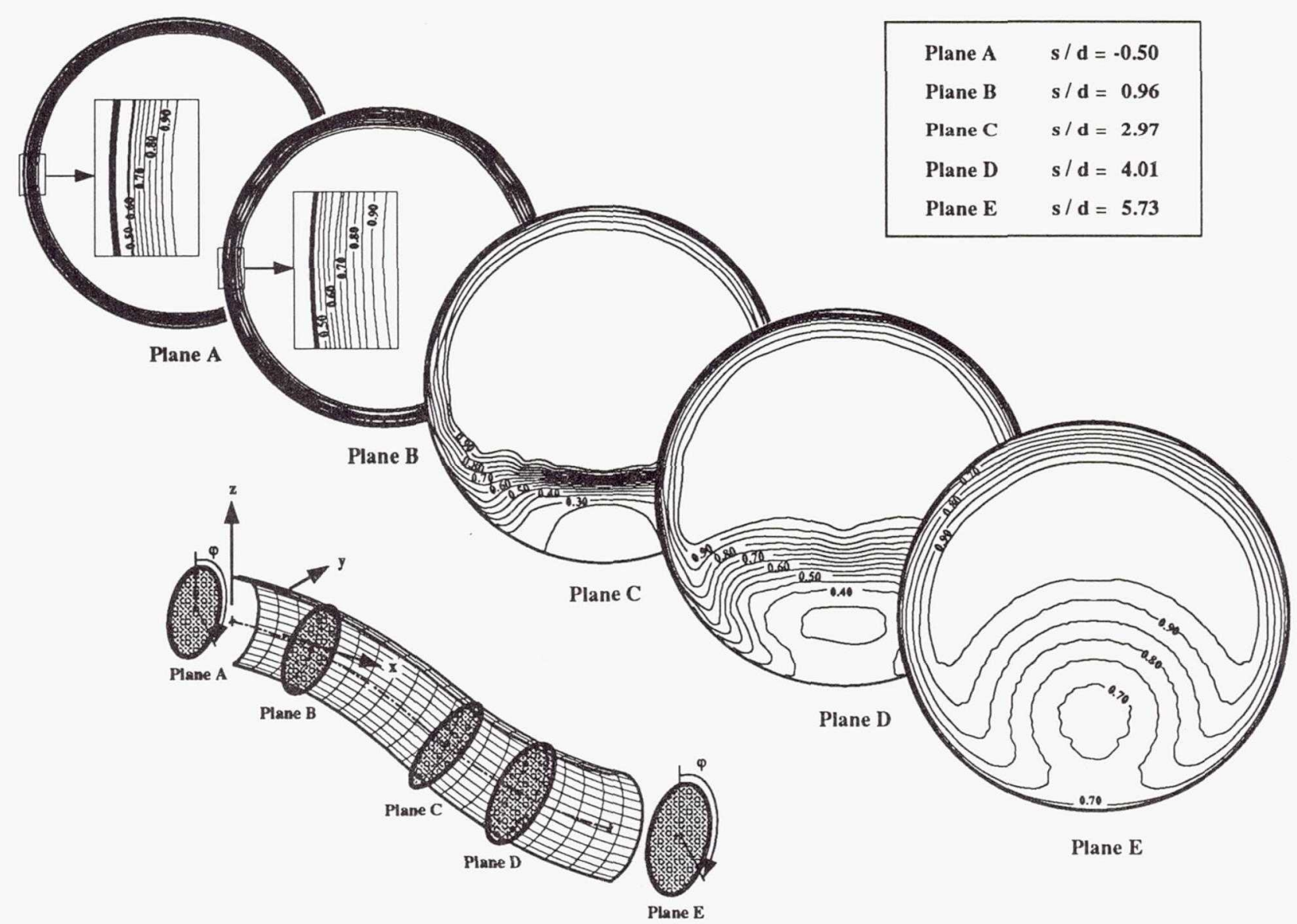

Fig. 10 Total pressures in the five measurement planes.

Contours of the normal components of velocity at all five planes are displayed in Fig. 11. An expanded view of the inlet boundary layer is presented for Plane A. A large region of low momentum fluid can be seen developing in the last three planes. Planes $\mathrm{C}$ and $\mathrm{D}$ lie within the region of separation. However, at the lowest contour level of the normal velocity component it was impossible to ascertain with a five-hole probe whether the flow was reversed. The distributions of the normal velocity component and total pressure are quite similar.

Finally, the transverse velocity components are plotted in Fig. 12 for the last four planes only. Data for the inlet plane (A) is not shown since cross flows were not detected there. The generation of strong transverse flows within the duct can be easily seen.

The flow field at Plane A corresponds to a developing pipe flow. The results in Fig. 3 verify the boundary layer is fully turbulent. Both the normal velocity and total pressure contours, shown for Plane A in Figs. 10 and 11 , show no circumferential variance.

As the flow progressed downstream, static pressure distributions developed from core flow adjusting to duct geometry and interacting with the separated region. Initially the S-duct deflected the incoming flow downward, which created large cross-stream pressure gradients. The static pressure distribution at Plane B in Fig. 9 shows the maximum static pressure value at the top of the duct $\left(\phi=0^{\circ}\right)$ and the minimum at the bottom of the duct $\left(\phi=180^{\circ}\right)$. The normal velocity distribution at Plane $B$ in Fig. 11 again shows the effect of streamline curvature. At the top of the duct, where the cross-stream pressure gradient is the greatest, there existed an adverse streamwise pressure gradient that decelerated the flow. Likewise at the bottom of the duct, where the minimum cross-stream pressure is located, there existed a favorable streamwise pressure gradient upstream which accelerated the flow. This can be seen in Fig. 11, where the local Mach number exceeded the inlet Mach number near the bottom of the duct. The transverse velocity components in Fig. 12 show that the cross flow occurred only near the duct surface. This was caused by the pressure gradient turning the lower momentum fluid towards the bottom of the duct. This was also detected in flow visualization. There was little change in the total pressure distribution at Plane B, given in Fig. 10, other than a slight thickening of the boundary layer. The boundary layer thickness at Plane B did also vary slightly with circumferential position. The boundary layer thickness was 


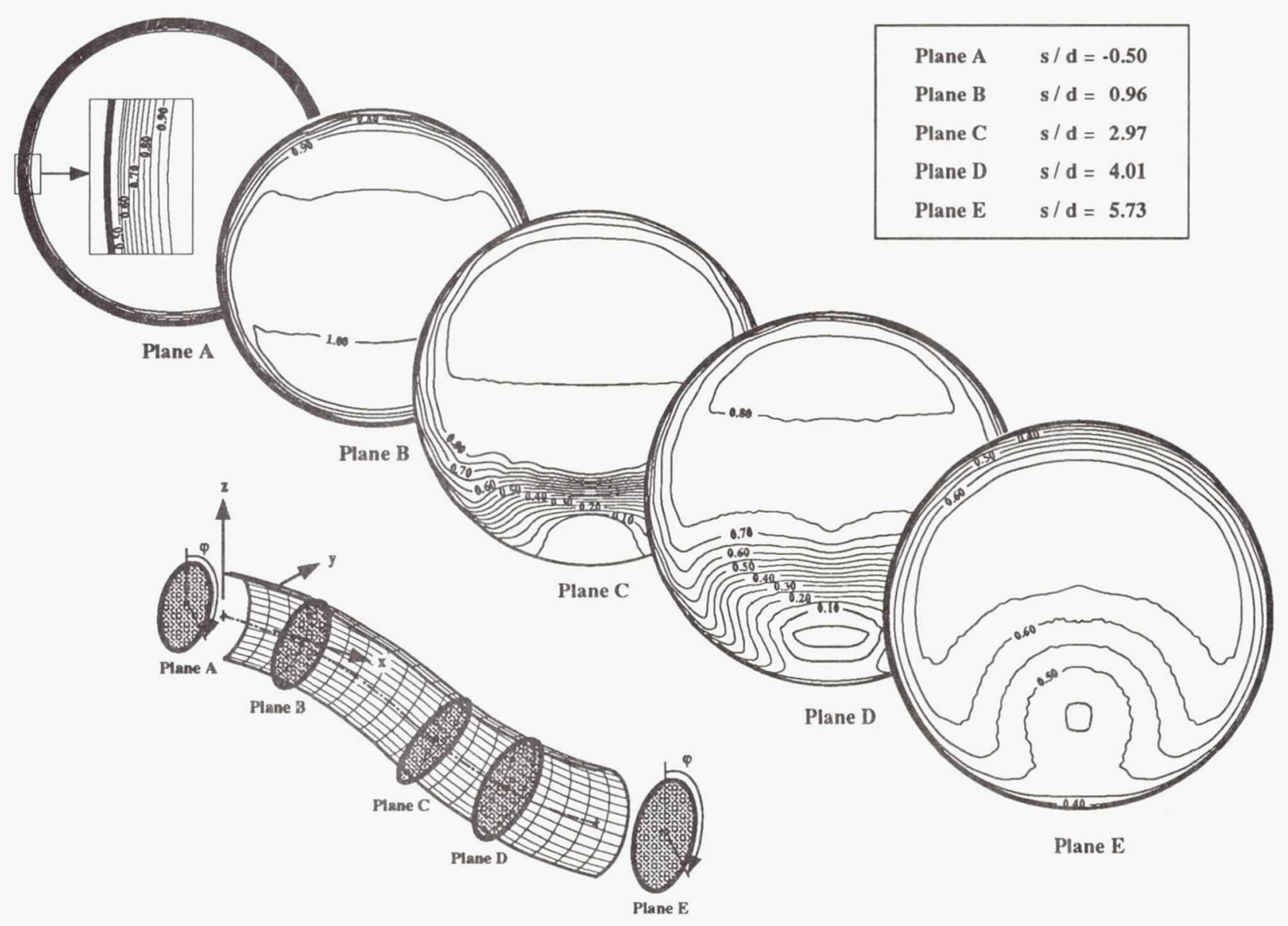

Fig. 11 Normal component of Mach vector in the five measurement planes.

greatest at $\phi=0^{\circ}$ and least at $\phi=180^{\circ}$. These phenomena can be attributed to the streamwise pressure gradients which accelerated the flow near the bottom of the duct and decelerated the flow near the top of the duct.

Near the middle of the S-duct the static pressure distribution should become nominally flat as the centerline curvature changes. In the second bend the orientation of the cross-stream static pressure distribution should reverse, so that the lowest static pressure is near the top and the highest static pressure is near the bottom of the duct. Both Planes C and D in Fig. 9 show this reversal. The static pressure distribution at Plane $\mathrm{C}$, which was located closer to the middle of the duct and in the separated flow region, was flatter than the distribution at Plane D. Both distributions indicate that an area of minimal change in flow speed or direction was present in the lower half of the duct, confirming the previous conclusion speculated from the surface pressure data. Normal velocity components (Fig. 11) and total pressure distributions (Fig. 10) show that a low velocity region existed in Planes $\mathrm{C}$ and $\mathrm{D}$ in the lower half of the duct. This region was cause by reversed flow and the convection of boundary layer fluid toward the lower surface. Strong pressure-driven cross flows existed near the lower duct surface in Planes $\mathrm{C}$ and
D (Fig. 12). These cross flows continually drove boundary layer fluid into the separated region. Enough low momentum fluid was convected upwards to form a local minimum of total pressure and normal velocity away from the surface. This suggests that a vortical structure was developing between Planes C and D. A significant amount of flow deflection at the centerline in Plane C is shown in Fig. 12. The deflection was a direct consequence of the blockage created by separation. This confirms the results obtained from the flow visualization on the centerline splitter plane. The core flow returned to the nominal streamwise direction by Plane $\mathrm{D}$, which is contrary to the splitter plane patterns. This inconsistency is a result of the pressure gradients which drove the build up of boundary layer fluid on the splitter plate toward the top of the duct, as previously explained.

By Plane $E$ the free stream flow returned nominally to the $\mathrm{x}$-direction. Cross-stream static pressure gradients were eliminated. However, before reaching the exit plane (E), static pressure gradients were strong enough to reverse the direction of the boundary layer fluid on the upper surface of the duct, as seen in Plane E (Fig. 12). A large pair of counter-rotating vortices, located in the lower half of Plane E, also evolved. These vortices con- 


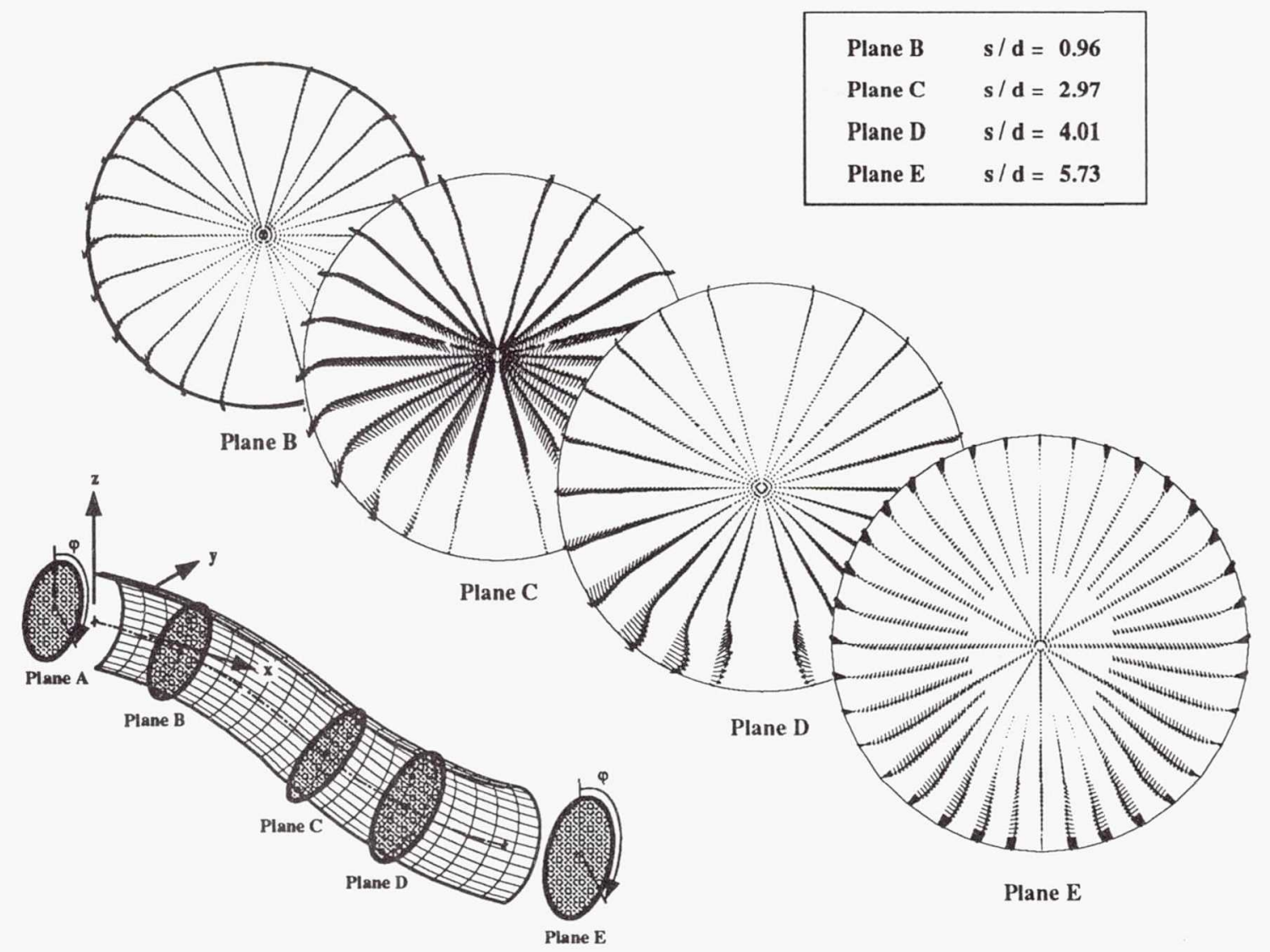

Fig. 12 Transverse components of Mach vector in four measurement planes.

tinually convected the low momentum fluid of the boundary layer towards the center of the duct. This convection degraded both the uniformity and magnitude of the total pressure profile. The region of low momentum fluid in Plane E (Fig. 10 and 11) extend above the center line.

\section{Summary}

The flow through the S-duct evolved from a strong interaction between the boundary layer and the core flow. Results show the flow was symmetric about the $x-z$ plane. A large region of streamwise flow separation occurred within the duct. Duct curvature induced strong pressuredriven secondary flows, which evolved into a large pair of counter-rotating vortices. These vortices convected the low momentum fluid of the boundary layer towards the center of the duct, degrading both the uniformity and magnitude of the total pressure profile. The benchmark data collected should be beneficial to inlet designers and is suitable for code validation.

\section{Acknowledgment}

The authors express their appreciation to NASA-
Lewis Research Center, Cleveland, Ohio, who sponsored this work under Grant No. NAG 3-1275. In addition, the authors would like to acknowledge the personnel without whose support this research endeavor would not have been possible. In particular the authors would like to thank Mr. B. Davis, Ms. K. Hall, Mr. B. Darby, Mr. M. Peters, Dr. B. Wendt and Dr. W. Hingst for their advice, support and assistance.

\section{References}

${ }^{1}$ Bansod, P. and Bradshaw, P., "The Flow in S-shaped Ducts," Aeronautical Quarterly, Vol. 23, May 1972, pp. 131-140.

${ }^{2}$ Guo, R. W. and Seddon, J., "The Investigations of Swirl in an S-duct," Aeronautical Quarterly, Vol. 33, May 1982, pp. 25-58.

${ }^{3}$ Taylor, A. M. K. P., Whitelaw, J. H., and Yianneskis, M., "Developing Flow in S-Shaped Ducts II - Circular Cross-Section Duct," Imperial College of Science and Technology NASA Contractor Report 3759, Feb. 1984.

${ }^{4}$ Vakili, A. D., Wu, J. M., Liver, P., and Bhat, M. K., "Experimental Investigation of Secondary Flows in a 
Diffusing S-Duct," The University of Tennessee Space Institute Tech. Rep. UTSI 86/14, 1984.

${ }^{5}$ Harloff, G. J., DeBonis, J. R., Smith, C. F., and Bruns, J. E., "Three-Dimensional Turbulent Computations for a Nondiffusing S-Duct," NASA CR 4391, 1991.

${ }^{6}$ Harloff, G. J., Smith, C. F., Bruns, J. E., and DeBonis, J. R., "Navier-Stokes Analysis of Three-Dimensional SDucts," Submitted to AIAA Joumal of Aircraft.

${ }^{7}$ Smith, C. F., Bruns, J. E., Harloff, G. J., and Debonis, J. R., "Three-Dimensional Compressible Turbulent Computations for a Diffusing S-Duct," Sverdrup Technology, Inc. NASA CR 4392, 1991.

${ }^{8}$ Towne, C. E. and Anderson, B. H., "Numerical Simulation of Flows in Curved Diffusers with Cross-Sectional Transitioning Using a Three-Dimensional Viscous Analysis," AIAA paper, 1981. (also NASA TM 81672).

${ }^{9}$ Towne, C. E., "Computation of Viscous Flow in Curved Ducts and Comparison with Experimental Data," AIAA Paper 84-0531, 1984.
${ }^{10}$ Vakili, A., Wu, J. M., Hingst, W. R., and Towne, C. E., "Comparison of Experimental and Computational Compressible Flow in a S-Duct," AIAA Paper 84-0033, 1984.

${ }^{11}$ Povinelli, L. A. and Towne, C. E., "Viscous Analysis of Flow Through Subsonic and Supersonic Intakes," NASA TM 88831, 1986.

${ }^{12}$ Reichert, B. A., Hingst, W. R., and Okiishi, T. H., "An Experimental Comparison of Nonswirling and Swirling Flow in a Circular-to-Rectangular Transition Duct," AIAA Paper 91-0342, 1991. (also NASA TM 104359).

${ }^{13}$ Sirbaugh, J. R. and Reichert, B. A., "Computation of a Circular-to-Rectangular Transition Duct Flow Field," AIAA Paper 91-1741, 1991.

${ }^{14}$ Porro, A. R., Hingst, W. R., Wasserbauer, C. A., and Andrews, T. B., "The NASA Lewis Research Center Internal Fluid Mechanics Facility," NASA TM 105187, Sept. 1991. 
Public reporting burden for this collection of information is estimated to average 1 hour per response, including the time for reviewing instructions, searching existing data sources, gathering and maintaining the data needed, and completing and reviewing the collection of information. Send comments regarding this burden estimate or any other aspect of this collection of information, including suggestions for reducing this burden, to Washington Headquarters Services, Directorate for information Operations and Reports, 1215 Jefferson Davis Highway, Suite 1204, Arlington, VA 22202-4302, and to the Office of Management and Budget, Paperwork Reduction Project (0704-0188), Washington, DC 20503.

\begin{tabular}{|l|l|l|}
\hline 1. AGENCY USE ONLY (Leave blank) & $\begin{array}{c}\text { 2. REPORT DATE } \\
\text { August } 1992\end{array}$ & $\begin{array}{r}\text { 3. REPORT TYPE AND DATES COVERED } \\
\text { Technical Memorandum }\end{array}$ \\
\hline
\end{tabular}

4. TITLE AND SUBTITLE

An Experimental Investigation of the Flow in a Diffusing S-Duct

6. AUTHOR(S)

Steven R. Wellborn, Bruce A. Reichert, and Theodore H. Okiishi
5. FUNDING NUMBERS

WU-505-62-52

\section{PERFORMING ORGANIZATION NAME(S) AND ADDRESS(ES)}

National Aeronautics and Space Administration

Lewis Research Center

Cleveland, Ohio 44135-3191
8. PERFORMING ORGANIZATION REPORT NUMBER

E-7240
9. SPONSORING/MONITORING AGENCY NAMES(S) AND ADDRESS(ES)

National Aeronautics and Space Administration

Washington, D.C. 20546-0001
10. SPONSORING/MONITORING AGENCY REPORT NUMBER

NASA TM-105809

AIAA-92-3622

\section{SUPPLEMENTARY NOTES}

Prepared for the 28th Joint Propulsion Conference and Exhibit cosponsored by the AIAA, SAE, ASME, and ASEE, Nashville, Tennessee, July 6-8, 1992. Steven R. Wellborn and Theodore H. Okiishi, Iowa State University, Ames, Iowa 50010; and Bruce A. Reichert, NASA Lewis Research Center, Cleveland, Ohio. Responsible person, Bruce A. Reichert (216) 433-8397.

12a. DISTRIBUTION/AVAILABILITY STATEMENT

12b. DISTRIBUTION CODE

Unclassified - Unlimited

Subject Category 07

\section{ABSTRACT (Maximum 200 words)}

Compressible, subsonic flow through a diffusing S-duct has been experimentally investigated. Benchmark aerodynamic data are presented for flow through a representative S-duct configuration. The collected data would be beneficial to aircraft inlet designers and is suitable for the validation of computational codes. Measurements of the three dimensional velocity field and total and static pressures were obtained at five cross-sectional planes. Surface static pressures and flow visualization also helped to reveal flow field characteristics. All reported tests were conducted with an inlet centerline Mach number of 0.6 and a Reynolds number, based on the inlet centerline velocity and duct inlet diameter, of $2.6 \times 10^{6}$. The results show that a large region of streamwise flow separation occurred within the duct. Details about the separated flow region, including mechanisms which drive this complicated flow phenomenon, are discussed. Transverse velocity components indicate that the duct curvature induces strong pressure driven secondary flows, which evolve into a large pair of counter-rotating vortices. These vortices convect the low momentum fluid of the boundary layer towards the center of the duct, degrading both the uniformity and magnitude of the total pressure profile.

\begin{tabular}{|c|c|c|}
\hline $\begin{array}{c}\text { 14. SUBJECT TERMS } \\
\text { Inlet flow; Intake systems; Engine inlets }\end{array}$ & $\begin{array}{c}\text { 19. SECURITY CLASSIFICATION } \\
\text { OF ABSTRACT } \\
\text { Unclassified }\end{array}$ \\
\hline $\begin{array}{c}\text { 17. SECURITY CLASSIFICATION } \\
\text { OF REPORT } \\
\text { Unclassified }\end{array}$ & $\begin{array}{c}\text { 18. SECURITY CLASSIFICATION } \\
\text { OF THIS PAGE } \\
\text { Unclassified }\end{array}$ &
\end{tabular}

